\title{
Escherichia coli verotoxigénica: modelo cuantitativo de exposición y escenarios de riesgos en canales bovinas en Argentina
}

\author{
Adib Olvera, ${ }^{1}$ Marcelo Signorini ${ }^{2}$ y Héctor Tarabla ${ }^{2}$
}

Forma de citar

Olvera A, Signorini M, Tarabla H. Escherichia coli verotoxigénica: modelo cuantitativo de exposición y escenarios de riesgos en canales bovinas en Argentina. Rev Panam Salud Publica. 2010;27(6):403-13.

RESUMEN Objetivos. Cuantificar la contaminación por Escherichia coli verotoxigénica asociada con el síndrome urémico hemolítico (ECvt-SUH) en las canales de ganado bovino y generar estimaciones de exposición en tres escenarios probables.

Métodos. Se modeló la frecuencia y la magnitud de la contaminación por ECvt-SUH desde la producción primaria hasta la salida de las canales del frigorífico, a partir de la información científica publicada y datos epidemiológicos y de expertos locales. Las distribuciones de la probabilidad que mejor describieron cada paso del proceso y los escenarios se incorporaron en el programa@Risk ${ }^{\circledR}$,con simulaciones múltiples mediante el análisis Monte Carlo. Para el análisis de sensibilidad se aplicó la prueba de correlación de Pearson.

Resultados. La frecuencia estimada de canales con ECvt-SUH fue 0,37 (IC95\%: 0,26 a 0,58) y la carga final de ECvt-SUH fue 0,47 log ufc/canal (IC95\%:-2,46 a 3,62). Las variables más fuertemente relacionadas fueron: el sistema de engorde $(\mathrm{r}=-0,681)$ y la concentración teórica de ECvt-SUH en la piel de los bovinos $(\mathrm{r}=0,702)$. La vacunación de los animales redujo en 54,1\% la frecuencia de ECvt-SUH en las canales, aunque la carga final de ECvtSUH no sufrió cambios significativos. El duchado de las canales redujo la carga final en 0,42 $\log u f c / c a n a l$ con respecto al modelo basal, sin modificar la frecuencia. Un incremento en la proporción de animales engordados en corrales hasta 50-60\% aumentaría un 15-23\% la frecuencia de canales contaminadas con ECvt-SUH.

Conclusiones. La vacunación de los animales resultó el escenario más eficaz para reducir el ingreso de la bacteria en la cadena agroindustrial de la carne bovina. La intensificación de la producción ganadera incrementará el riesgo a la salud pública por una mayor exposición a ECvt-SUH.

Palabras clave Escherichia coli shiga-toxigénica; síndrome hemolítico-urémico; industria de la carne; medición de riesgo; Argentina.

Las enfermedades transmitidas por los alimentos constituyen un problema

\footnotetext{
Escuela Superior de Ciencias Agropecuarias, Universidad Autónoma de Campeche, Campeche, México.

2 Consejo Nacional de Investigaciones Científicas y Técnicas, Rafaela, Santa Fe, Argentina. La correspondencia se debe dirigir a Marcelo Signorini, Consejo Nacional de Investigaciones Científicas y Técnicas, Ruta 34 km 227, Rafaela, Santa Fe 2300, Argentina. Correo electrónico: marcelo.signorini@ gmail.com
}

de salud pública mundial que se incrementa año tras año. Entre los factores responsables se destacan el crecimiento de la población, la pobreza, la urbanización en los países subdesarrollados, el comercio internacional de alimentos y la aparición de nuevos agentes causantes de enfermedades transmitidas por alimentos o nuevas variantes de estas con mayor resistencia y patogenicidad $(1,2)$.
Entre los agentes involucrados en estas enfermedades se destaca la enterobacteria Escherichia coli verocitotoxigénica (ECvt), que puede causar diarreas, síndrome urémico hemolítico (SUH) e incluso la muerte (2-7). Generalmente, la transmisión de ECvt está asociada con la carne bovina cruda o insuficientemente cocida, por ser un reservorio natural de esta bacteria (2), en particular de serotipos de ECvt asociados con el SUH (ECvt-SUH). 
El SUH es endémico en Argentina y constituye la primera causa de insuficiencia renal aguda y la segunda de insuficiencia renal crónica en niños; además es responsable de alrededor de $20 \%$ de los trasplantes renales en niños y adolescentes (8). Argentina tiene la mayor incidencia de SUH en el mundo, con 13,9 casos por 100000 niños $(8,9)$ y anualmente se registran aproximadamente 400 casos nuevos; los casos notificados entre 1965 y 2010 suman más de 7000 (8-12).

Se han propuesto diversas medidas de gestión para reducir los riesgos del consumo de alimentos contaminados con ECvt-SUH, como el uso de probióticos y bacteriófagos, modificaciones en la dieta y el uso de vacunas $(2,8,9,13)$. Al igual que con otras amenazas a la salud presentes en los alimentos, estas medidas se deben analizar en el contexto de la cadena de producción y elaboración para cuantificar el efecto de los diferentes pasos del proceso sobre la probabilidad de adquirir la infección (14).

Los objetivos de este trabajo fueron cuantificar la frecuencia y la magnitud de la contaminación por ECvt-SUH desde la producción primaria hasta la salida de las canales del frigorífico y generar estimaciones de exposición en tres escenarios probables: la vacunación de las reses, la descontaminación de las canales y el sistema de engorde.

\section{MATERIALES Y MÉTODOS}

\section{Descripción del modelo teórico}

Se modeló la frecuencia y la concentración de la contaminación por ECvt desde la producción primaria de bovinos hasta la canal a la salida del frigorífico. Para la construcción del modelo se recurrió a la información científica publicada sobre este germen patógeno y datos estadísticos y epidemiológicos, preferentemente de Argentina. Cuando no se encontró la información buscada, se utilizó la generada en otros países y la opinión de expertos locales. El modelo de simulación estocástico se creó en Microsoft Excel 2007 y @Risk ${ }^{\circledR}$ (versión 4.0, Palisade Corporation, New York, Estados Unidos de América) y se realizaron 5000 iteraciones con la técnica de simulación Monte Carlo.

Las dos variables de interés (medidas de resultado) del modelo fueron la proporción de canales contaminadas con ECvt-SUH y la magnitud de esa carga bacteriana, a la salida del frigorífico.

CUADRO 1. Parámetros de entrada empleados en el modelo de exposición a Escherichia coli verotoxigénica (ECvt) en canales bovinas en la etapa de producción primaria

\begin{tabular}{|c|c|c|c|}
\hline Código & Variable & Categoría & Distribución/modelo \\
\hline$P_{\text {pas }}$ & Proporción de animales engordados en pastoreo & Probabilidad & 0,797 \\
\hline $\mathrm{Pb}_{\mathrm{P}-\mathrm{F}}$ & $\begin{array}{l}\text { Sistema de engorde: probabilidad de que un animal } \\
\text { sea engordado en pastoreo (1) o corrales de } \\
\text { engorde }(0)\end{array}$ & Probabilidad & Binomial $\left(1, P_{\text {pas }}\right)$ \\
\hline $\mathrm{Pv}_{\mathrm{p}}$ & $\begin{array}{l}\text { Frecuencia de ECvt en el sistema de engorde por } \\
\text { pastoreo }\end{array}$ & Incertidumbre & Beta $(115,182)$ \\
\hline $\mathrm{Pb}_{\mathrm{Pvp}}$ & $\begin{array}{l}\text { Probabilidad de que un animal de pastoreo esté } \\
\text { liberando ECvt en sus heces }\end{array}$ & Probabilidad & Binomial $\left(1, P v_{p}\right)$ \\
\hline$P v_{f}$ & Frecuencia de ECvt en los corrales de engorde & Incertidumbre & Beta $(38,23)$ \\
\hline $\mathrm{Pb}_{\mathrm{Pvf}}$ & $\begin{array}{l}\text { Probabilidad de que un animal en corrales de } \\
\text { engorde esté liberando ECvt en sus heces }\end{array}$ & Probabilidad & Binomial $\left(1, \mathrm{Pv}_{\mathrm{f}}\right)$ \\
\hline$P v_{\text {ESUH }}$ & Frecuencia de cepas de ECvt asociadas con el SUH & Incertidumbre & Beta $(45,25)$ \\
\hline $\mathrm{Pb}_{\mathrm{pESUH}}$ & $\begin{array}{l}\text { Probabilidad de que un animal engordado en } \\
\text { pastoreo esté liberando ECvt asociadas con el SUH }\end{array}$ & Probabilidad & $P v_{p} \times P v_{p E S U H}$ \\
\hline $\mathrm{Pb}_{\text {fESUH }}$ & $\begin{array}{l}\text { Probabilidad de que un animal engordado en } \\
\text { corrales esté liberando ECvt asociadas con el SUH }\end{array}$ & Probabilidad & $P v_{f} \times P v_{p E S U H}$ \\
\hline
\end{tabular}

\section{Evaluación de la exposición}

Para este estudio, la cadena agroindustrial se dividió en dos etapas: producción primaria y frigorífico.

Producción primaria. Dado que la frecuencia de ECvt en los bovinos depende del sistema de engorde empleado, se estimó la probabilidad $\left(\mathrm{Pb}_{\mathrm{P}-\mathrm{F}}\right)$ de que un animal sea engordado en un sistema extensivo (pastoreo) o en corrales de engorde (sistema conocido como feedlot). Se emplearon datos de la Oficina Nacional de Control Comercial Agropecuario sobre la producción de bovinos en Argentina en diferentes sistemas (15), ajustados a una distribución binomial (cuadro 1).

Para modelar la frecuencia (expresada como una proporción simple del número de canales contaminadas entre el número total de canales) de ECvt en cada sistema de engorde se emplearon los resultados de estudios realizados en Argentina en sistema de pastoreo (16-18) y uno realizado en corrales de engorde (19). La frecuencia de ECvt en el sistema de pastoreo fue variable, con valores de $22,0 \%$ (16), 44,1\% (17) y $69,0 \%$ (18). El único dato de frecuencia de ECvt en los corrales de engorde (19) fue de 62,7\%. La variable sistema de engorde se ajustó a una distribución binomial, con la incorporación de la incertidumbre en los datos a partir de una distribución beta.

La virulencia de las cepas de ECvt está relacionada con el tipo de toxina producida, ya sea VT1, VT2 o sus variantes
(19). En un trabajo previo, $51,2 \%$ de las cepas de ECvt aisladas en heces bovinas en Argentina pertenecían a uno de los 16 serotipos asociados con diarrea sanguinolenta y SUH (18). Esta información se empleó para ajustar la frecuencia de ECvt-SUH (Pv ESUH $)$ mediante una distribución beta (cuadro 1). La transportación de los animales es la etapa que articula la producción primaria con el frigorífico. Dado que este trasladado no genera cambios en la contaminación con ECvt (20), no se incorporó al modelo.

Frigorífico. Todos los frigoríficos de bovinos en Argentina siguen procedimientos de sacrificio y faenado similares (21). La frecuencia y la carga de ECvt se modelaron a lo largo de las diferentes etapas del frigorífico, desde el arribo de los animales vivos hasta que las canales salen del almacenamiento refrigerado. Estas etapas y sus características generales corresponden a frigoríficos aprobados por la autoridad sanitaria argentina, cuyos productos se destinen tanto al mercado interno como a la exportación.

Dado que la ECvt no genera enfermedades en los bovinos, la infección no se puede detectar durante la inspección antemortem $\mathrm{y}$, por lo tanto, esta etapa no se incorporó al modelo (11).

El desollado es la etapa más crítica para la contaminación de las canales con ECvt y se estima que la transferencia de bacterias de la piel a la carne es inevitable $(9,22-25)$. Se consideró que todo animal que excrete ECvt en las heces tendrá su 
canal contaminada y podrá infectar otras canales durante el proceso de desollado. Para estimar la tasa de contaminación cruzada $\left(\mathrm{T}_{\mathrm{CC}}\right)$ se emplearon datos publicados de frecuencia de ECvt en las heces, la piel y las canales de bovinos en los frigoríficos (26). Se generaron dos distribuciones beta para modelar la incertidum- bre en la frecuencia de animales que excretan ECvt en las heces (Mhp $\mathrm{PS}$ ) y la frecuencia de canales positivas $\left(\mathrm{Mcp}_{\mathrm{PE}}\right)$ antes de la evisceración. La $\mathrm{T}_{\mathrm{CC}}$ se calculó como la razón entre las dos frecuencias $\left(\right.$ Mcp $\left._{\mathrm{PE}} \mathrm{y} \mathrm{Mhp}_{\mathrm{PS}}\right)$. Con la $\mathrm{T}_{\mathrm{CC}}$ se modeló la proporción de canales contaminadas con ECvt-SUH (PCV $\mathrm{SUH}_{\mathrm{S}}$ ) (cuadro 2).
La probabilidad de enfermar y la magnitud del daño ocasionado por ECvt$\mathrm{SUH}$ en las personas dependen en gran parte del número de bacterias consumidas. Por ello se modeló la concentración teórica de ECvt-SUH en la piel del bovino $\left(\mathrm{C}_{\mathrm{VTP}}\right)$ a partir de datos publicados previamente (27) (cuadro 2).

CUADRO 2. Parámetros de entrada empleados en el modelo de exposición a Escherichia coli verotoxigénica (ECvt) en canales bovinas en la etapa de frigorífico

\begin{tabular}{|c|c|c|c|c|}
\hline Código & Variable & $\begin{array}{l}\text { Tipo de } \\
\text { variable }\end{array}$ & $\begin{array}{l}\text { Unidad de } \\
\text { medida }\end{array}$ & Distribución/modelo \\
\hline $\mathrm{Mhp}_{\mathrm{PS}}$ & Muestras de heces positivas antes del sacrificio & Incertidumbre & $N A^{a}$ & Beta $(92,237)$ \\
\hline $\operatorname{Mcp}_{\mathrm{PE}}$ & Muestras de canales positivas antes de la evisceración & Incertidumbre & NA & Beta $(149,194)$ \\
\hline $\mathrm{T}_{\mathrm{CC}}$ & Tasa de contaminación cruzada & Proporción & $\mathrm{ufc}^{\mathrm{b}}$ & $\mathrm{Mcp}_{\mathrm{PE}} / \mathrm{Mhp}_{\mathrm{PS}}$ \\
\hline $\mathrm{PCV}_{\mathrm{SUH}}$ & Proporción de canales con ECvt asociadas con el SUH & $\begin{array}{l}\text { Medida de } \\
\text { resultado }\end{array}$ & NA & $\left(\mathrm{T}_{\mathrm{CC}} \times \mathrm{Pb}_{\mathrm{pESUH}}\right) /\left(\left(1-\mathrm{Pb}_{\mathrm{pESUH}}\right)+\left(\mathrm{Pb}_{\mathrm{pESUH}} \times \mathrm{T}_{\mathrm{CC}}\right)\right)$ \\
\hline $\mathrm{C}_{\mathrm{VTP}}$ & $\begin{array}{l}\text { Concentración teórica de ECvt-SUH en la piel de } \\
\text { bovinos }\end{array}$ & Proporción & $\mathrm{ufc} / \mathrm{cm}^{2}$ & Acumulativa $(-1,5 ; 6,0 ; 6,0 ; 0,2 ; 1,0)$ \\
\hline $\mathrm{Pvt}_{\mathrm{NoM}}$ & $\begin{array}{l}\text { Proporción de ECvt-SUH no consideradas en el } \\
\text { muestreo }\end{array}$ & Incertidumbre & ufc/cm² & Uniforme $(0,2 ; 1,74)$ \\
\hline $\mathrm{CR}_{\mathrm{VTP}}$ & Concentración real de ECvt-SUH en la piel de bovinos & Proporción & $\log u f c / \mathrm{cm}^{2}$ & $\mathrm{C}_{\mathrm{VTP}}+\mathrm{Pvt}_{\mathrm{NoM}}$ \\
\hline $\mathrm{FT}_{\mathrm{PC}}$ & Factor de transferencia de ECvt-SUH de la piel a la canal & Incertidumbre & $\mathrm{ufc} / \mathrm{cm}^{2}$ & Normal $(2,33 ; 1 ;$ truncada $(0 ; 4,4))$ \\
\hline $\mathrm{CVT}_{\mathrm{TC}}$ & $\begin{array}{l}\text { Concentración de ECvt-SUH que se transfiere de la } \\
\text { piel a la canal }\end{array}$ & Proporción & $\mathrm{ufc} / \mathrm{cm}^{2}$ & $\mathrm{CR}_{\mathrm{VTP}}-\mathrm{FT}_{\mathrm{PC}}$ \\
\hline $\mathrm{CR}_{\mathrm{VTC}}$ & $\begin{array}{l}\text { Concentración final de ECvt-SUH que pasa de la piel a } \\
\text { la canal }\end{array}$ & Proporción & $\log \mathrm{ufc} / \mathrm{cm}^{2}$ & $\log \left(\left(\right.\right.$ Potencia $\left.\left.\left(10,\left(\mathrm{CVT}_{\mathrm{TC}}\right)\right)\right) / 100\right)$ \\
\hline $\mathrm{S}_{\mathrm{c}}$ & Superficie de una canal bovina & Proporción & $\mathrm{cm}^{2}$ & Triangular (2 034, 5 200, 6412$)$ \\
\hline Esc & Estimación de la superficie contaminada de una canal & Incertidumbre & $\mathrm{cm}^{2}$ & Triangular $\left(30,300, \mathrm{~S}_{\mathrm{c}}\right)$ \\
\hline $\mathrm{NVT}_{\mathrm{EC}}$ & Concentración de ECvt en la canal & Proporción & $\log$ ufc/cm² & $\log \left(\right.$ Potencia $\left(10,\left(\mathrm{CR}_{\mathrm{VTC}}\right)\right) \times$ Esc $)$ \\
\hline $\mathrm{RpL}$ & Reducción más probable por el efecto del lavado & Proporción & $\log$ ufc/cm² & Uniforme $(0,3 ; 0,7)$ \\
\hline RPpL & Rango máximo de reducción por efecto del lavado & Proporción & $\log$ ufc/cm² ${ }^{2}$ & Uniforme $(0,8 ; 1,2)$ \\
\hline $\mathrm{MR}_{\mathrm{V}} \mathrm{L}$ & Modelo de reducción de ECvt-SUH por el lavado & Incertidumbre & $\log \mathrm{ufc} / \mathrm{cm}^{2}$ & Triangular (0, RpL, RPpL) \\
\hline $\mathrm{CR}_{\mathrm{V}} \mathrm{L}$ & Concentración real de ECvt-SUH después del lavado & Proporción & $\log$ ufc/cm² & $\mathrm{NVT}_{\mathrm{EC}}-\mathrm{MR}_{\mathrm{V}} \mathrm{L}$ \\
\hline $\mathrm{T}_{\mathrm{CR}}$ & Temperatura en la cámara de refrigeración & Variabilidad & ${ }^{\circ} \mathrm{C}$ & Triangular $(2,4,6)$ \\
\hline $\mathrm{T}_{\mathrm{ECRC}}$ & $\begin{array}{l}\text { Tiempo de estancia de la canal en la cámara de } \\
\text { refrigeración }\end{array}$ & Variabilidad & horas & Triangular $(24,48,96)$ \\
\hline $\mathrm{E}_{\mathrm{FL}}$ & Ecuación de la fase de latencia & Relación & horas & $10,169+\left(-2,768 \times \operatorname{Ln}\left(T_{C R}\right)\right)$ \\
\hline $\mathrm{ET}_{\mathrm{ExC}}$ & Ecuación de la tasa exponencial de crecimiento & Relación & horas $^{-1}$ & $-9,258+7,155 \times \operatorname{Ln}\left(\operatorname{Ln}\left(T_{C R}\right)\right)$ \\
\hline $\operatorname{Tlag}_{\mathrm{D}}$ & Tiempo de latencia en el crecimiento bacteriano & Incertidumbre & horas & Normal $\left(E_{F L} 1,0,147\right)$ \\
\hline $\mathrm{DT}_{\mathrm{ExC}}$ & Distribución de la tasa exponencial de crecimiento & Incertidumbre & horas $^{-1}$ & Normal $\left(\mathrm{ET}_{\mathrm{ExC}}, 0,25\right)$ \\
\hline $\mathrm{Flag}_{\mathrm{R}}$ & $\begin{array}{l}\text { Duración de la fase real de latencia del crecimiento } \\
\text { bacteriano }\end{array}$ & Incertidumbre & días & Exponencial $\left(\left(\operatorname{Tlag}_{D}\right) / 24\right)$ \\
\hline $\mathrm{TExC}_{\mathrm{R}}$ & Tasa exponencial de crecimiento real & Incertidumbre & horas $^{-1}$ & Exponencial $\left(\mathrm{DT}_{\mathrm{ExC}}\right)$ \\
\hline $\mathrm{C}_{\mathrm{Bmax}} \mathrm{P}$ & Concentración bacteriana máxima más probable & Probabilidad & $\log \mathrm{ufc} / \mathrm{cm}^{2}$ & Uniforme $(5,10)$ \\
\hline $\mathrm{C}_{\mathrm{Bmax}} \mathrm{R}$ & Concentración bacteriana máxima real & Incertidumbre & $\log$ ufc/cm² & Triangular $\left(5, \mathrm{P}_{\mathrm{Bmax}} \mathrm{P}, 10\right)$ \\
\hline MGpz & Modelo de Gompertz & Incertidumbre & $\log \mathrm{ufc} / \mathrm{cm}^{2}$ & 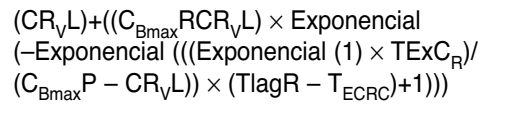 \\
\hline $\mathrm{CB}_{\mathrm{F}}$ & Carga bacteriana final en la canal & Incertidumbre & $\log$ ufc & $\mathrm{SI}\left(\mathrm{C}_{\mathrm{Bmax}} \mathrm{R}>\mathrm{Flag}_{\mathrm{R}}, \mathrm{CR}_{\mathrm{V}} \mathrm{L}, \mathrm{MGpz}\right)$ \\
\hline
\end{tabular}

a NA: no aplica por ser una categoría adimensional.

${ }^{\mathrm{b}}$ ufc: unidades formadoras de colonia. 
El número de ECvt-SUH recuperadas en los muestreos puede resultar subestimado en muchas ocasiones, entre otras razones por la baja sensibilidad de algunas pruebas utilizadas (26). Por ello, se modeló la proporción de ECvt-SUH no consideradas en el muestreo a partir de resultados publicados (27), ajustada a una distribución uniforme $\left(\mathrm{Pvt}_{\mathrm{NoM}}\right)$. $\mathrm{Al}$ sumar la $\mathrm{C}_{\mathrm{VTP}}$ y la $\mathrm{Pvt}_{\mathrm{NoM}}$ se obtiene la concentración real de ECvt-SUH en la piel de las reses $\left(\mathrm{CR}_{\mathrm{VTP}}\right)$. Para modelar la cantidad de ECvt-SUH que puede pasar de la piel contaminada a la canal durante el desollado (tasa de transferencia), se emplearon resultados previos (23). De esta forma se obtuvo el factor de transferencia que corresponde al número de ECvt-SUH que permanecen en la piel del bovino durante el desollado $\left(\mathrm{FT}_{\mathrm{PC}}\right)$.

Durante la evisceración puede haber ruptura de las vísceras y derramamiento del contenido gastrointestinal, pero no existe información científica que determine la frecuencia de este evento. Mediante la consulta a expertos se estimó que dicha probabilidad es muy baja y que, cuando ocurre, la canal se lava con agua a presión, se cortan las zonas sucias (verdes) y se aplica ácido láctico o acético (S. Bertero, comunicación personal, enero de 2009; C. Zurbrigen, comunicación personal, julio de 2009).

No existe información disponible para estimar la superficie total contaminada de una canal. Algunos autores determinaron dicha superficie arbitrariamente en una zona mínima de $30 \mathrm{~cm}^{2}$, una máxima de $3000 \mathrm{~cm}^{2}$ y una más probable de $300 \mathrm{~cm}^{2}(25,28)$. Con la finalidad de reducir las incertidumbres en el modelo, se procedió a estimar la superficie máxima que puede quedar contaminada en una canal. Para ello se seleccionaron treinta canales pertenecientes a diferentes categorías (toro, vaca, novillo y vaquillona), se midieron el largo de la canal desde la articulación társico-metatársica hasta la articulación carpo-metacarpiana y el ancho a la altura de la apófisis espinosa de la segunda vértebra dorsal hasta la superficie de la cuarta esternebra y se tomó una fotografía de la cara externa de la canal. Esta se introdujo en Photo Paint (Corel Draw Graphics Suite X4, Ottawa, Canadá) para calcular la superficie total de la canal. Para estimar la superficie máxima que se puede contaminar con ECvt se recurrió a un estudio (29) en el que se determinaron las regiones más contaminadas de la canal (cuello, glúteo, flanco y pecho). Los datos generados a partir de la sumatoria de las superficies de estas regiones anatómicas se ajustaron a una distribución triangular $\left(\mathrm{S}_{\mathrm{c}}\right)$ y se obtuvieron valores mínimo, más probable y máximo de $2034 \mathrm{~cm}^{2}, 5200 \mathrm{~cm}^{2}$ y $6412 \mathrm{~cm}^{2}$, respectivamente. Finalmente, mediante una distribución triangular (Esc) de la superficie contaminada de la canal se obtuvo un valor mínimo de $30 \mathrm{~cm}^{2}$ y más probable de $300 \mathrm{~cm}^{2}$; para el valor máximo se utilizó la distribución triangular $\mathrm{S}_{\mathrm{c}}$ que incorpora la incertidumbre.

El siguiente paso fue determinar la reducción de ECvt-SUH en las canales por el lavado con agua potable aplicada a presión (21). Algunos autores (30) indican que la reducción máxima alcanzable mediante este procedimiento, medida en logaritmos de unidades formadoras de colonia (ufc) por área, es incierta y puede variar entre 0,8 y $1,2 \log \mathrm{ufc} / \mathrm{cm}^{2}$, aunque los valores más probables estarían entre 0,3 y $0,7 \log \mathrm{ufc} / \mathrm{cm}^{2}$. El modelo de reducción de ECvt-SUH por el lavado $\left(\mathrm{MR}_{\mathrm{V}} \mathrm{L}\right)$ se ajustó a una distribución triangular, lo que generó un valor mínimo de cero y valores máximo y más probable inciertos. Para incorporar la incertidumbre en los dos parámetros se emplearon dos distribuciones uniformes, lo que llevó a un valor más probable de 0,3 a 0,7 $\log \mathrm{ufc} / \mathrm{cm}^{2}$ y un valor máximo de 0,8 a $1,2 \log \mathrm{ufc} / \mathrm{cm}^{2}$ (cuadro 2).

Después del duchado, las canales pasan a la cámara de oreo durante $30-40$ minutos (21), pero no existe información que sustente la posibilidad de un cambio en la frecuencia de canales contaminadas o la carga de ECvt-SUH en ellas. Posteriormente, las canales pasan a refrigeración donde se almacenan por no menos de 24 horas (29). La refrigeración puede afectar a las bacterias por la interacción de las bajas temperaturas y el agua aplicada durante el duchado (23, 30). La temperatura dentro de la cámara de refrigeración varía por diferentes causas, lo que puede generar cambios en la concentración de ECvt-SUH (24). Dado que no existe información científica que determine la amplitud de la variación térmica, se consultó a un especialista en el tema que estimó valores mínimo de $2{ }^{\circ} \mathrm{C}$, más probable de $4{ }^{\circ} \mathrm{C}$ y máximo de $6^{\circ} \mathrm{C}$ (C. Zurbrigen, comunicación personal, julio de 2009). Esta variable se modeló con una distribución triangular (cuadro 2).

El tiempo de exposición a las temperaturas de almacenamiento afecta al creci- miento bacteriano $(31,32)$; sin embargo, no existen datos sobre el tiempo que debe permanecer una canal dentro de las cámaras frigoríficas (29). A falta de una fuente publicada, para modelar esta variable se consultó a un especialista en el tema, que estimó que la estancia de la canal en la cámara de refrigeración $\left(\mathrm{T}_{\mathrm{ECRC}}\right)$ es de $24 \mathrm{~h}$ como mínimo con tiempos máximo de 96 h y más probable de 48 h (C. Zurbrigen, comunicación personal, julio de 2009). Esta información se modeló mediante una distribución triangular (cuadro 2).

El crecimiento de ECvt-SUH durante la refrigeración se modeló con una metodología ya descrita (31), basada en modelos de crecimiento secundarios y terciarios para ECvt en carne; así se modelaron los parámetros (fase de latencia, tasa máxima de crecimiento y concentración máxima teórica) de la ecuación de crecimiento de Gompertz.

Con las dos medidas de resultado - proporción de canales contaminadas con ECvt-SUH ( $\left.\mathrm{PCV}_{\mathrm{SUH}}\right)$ y la carga bacteriana final en ellas $\left(\mathrm{CB}_{\mathrm{F}}\right)$ - se hicieron 5000 iteraciones, según el sistema de muestreo hipercubo latino, y se graficaron los resultados.

\section{Análisis de sensibilidad}

Para determinar el impacto que tienen las variables de entrada del modelo sobre las medidas de resultado se realizó un análisis de sensibilidad mediante la prueba de correlación $(r)$ de Pearson. Se realizó un análisis avanzado de sensibilidad a las variables con mayor coeficiente de correlación con 5000 iteraciones del modelo. Para ello se mantuvo fijo el valor correspondiente a los percentiles $1,25,50,75,98$ y 99 (siete simulaciones con 5000 iteraciones cada una) para cada variable correlacionada y se dejó mover libremente el resto de las variables del modelo. Los valores extremos de probabilidad (percentiles 1 y 99) se utilizaron para calcular la razón de posibilidades (odds ratio, OR) de las variables de interés - como indicador de riesgo- y sus intervalos de confianza de 95\% (IC95\%).

\section{Análisis de escenarios}

El análisis de escenarios se basa en un grupo de supuestos relacionados con las variables de entrada del modelo y habitualmente se utiliza para describir eventos futuros posibles (33). Los escenarios 
se construyeron con las variables de interés con mayor correlación con las medidas de resultado del modelo, según el análisis de sensibilidad. Las estrategias de control aplicables a las etapas del proceso en las que están involucradas esas variables se seleccionaron a partir de la información científica publicada. Los resultados generados por cada uno de los tres escenarios escogidos se compararon con el modelo basal.

Escenario de la vacunación. El ganado bovino es el principal reservorio de ECvtSUH y ha estado involucrado en muchos brotes de SUH en humanos, tanto como alimento contaminado como por la contaminación del ambiente. Por lo tanto, la vacunación de estos animales durante la etapa de producción primaria podría ayudar a reducir el riesgo de exposición de las personas a ese germen patógeno.

Se modeló el efecto que generaría la vacunación sobre la frecuencia de ECvtSUH y el nivel de contaminación de las canales. Se estimó que como mínimo se podría alcanzar una cobertura de vacunación de $50 \%$ de los animales, aunque si algún organismo gubernamental - como el Ministerio de Salud - incentivara a los productores, esta proporción podría llegar a $80 \%$. Dada la incertidumbre en los datos, la variable se modeló con una distribución uniforme.

El siguiente paso fue determinar la probabilidad de que un animal vacunado esté verdaderamente inmunizado, para lo que se recurrió a la información publicada sobre vacunaciones en bovinos con proteínas secretadas por ECvt (Tir y EspA) (34). Los datos se ajustaron a una distribución beta que permitió modelar la incertidumbre.

Si bien no todos los animales vacunados quedan inmunizados, la carga de ECvt en las heces de animales vacunados no inmunes es menor en aproximadamente un nivel logarítmico que la de los animales no vacunados (34).

Escenario de la descontaminación de canales. En los frigoríficos de todo el mundo se realizan actividades sistemáticas dirigidas a reducir la carga de ECvt-SUH. Las más frecuentes, ya sea de forma individual o combinada, son la aspiración, la pasteurización por vapor y el lavado con soluciones orgánicas de ácido láctico, ácido peracético o ácido acético (3537). Esta última técnica se destaca debido a su bajo costo, fácil aplicación e inocuidad para la salud pública (37).
Para la construcción de este escenario se partió del supuesto de que en la totalidad de los frigoríficos se aplica el duchado de las canales con soluciones de ácidos orgánicos después de la evisceración. Para determinar la reducción de ECvt-SUH después del duchado se empleó la información científica previamente publicada (23).

Escenario del sistema de engorde empleado. El crecimiento de la agricultura en la Argentina está desplazando la ganadería hacia zonas menos favorables para la actividad pecuaria, lo que favorece el empleo de corrales de engorde, algo que tenderá a mantenerse en el futuro próximo $(15,38,39)$.

Para la construcción de este escenario se consideró que de 50 a $60 \%$ del total de bovinos destinados al consumo en los próximos años se criará en corrales de engorde. Esta estimación del escenario futuro se utilizó solamente para generar una proyección del riesgo de exposición a ECvt-SUH por el consumo de carne. Se ajustó la información a una distribución uniforme, lo que resultó en un riesgo mínimo de 0,5 y uno máximo de 0,6; este valor se incorporó a la distribución binomial del modelo basal para representar la probabilidad de salida de un bovino del sistema de corrales de engorde o de pastoreo.

\section{RESULTADOS}

La frecuencia de ECvt-SUH en bovinos antes de la faena en el frigorífico $\left(\mathrm{PCV}_{\mathrm{SUH}}\right)$ se estimó en 0,37 (IC95\%: 0,26 a 0,58$)$. Esto implica que, en promedio, por cada 100 animales faenados, 37 tendrían ECvt-SUH en sus canales. La carga final de ECvt-SUH en las canales a la salida de la cámara de refrigeración $\left(\mathrm{CB}_{\mathrm{F}}\right)$ se estimó en 0,47 log ufc/canal (IC95\%: $-2,46$ a 3,62) (figura 1).

\section{Análisis de sensibilidad}

Las variables con mayor impacto sobre la $\mathrm{PCV}_{\mathrm{SUH}}(P<0,05)$ fueron: el sistema de engorde $\left(\mathrm{Pb}_{\mathrm{P}-\mathrm{F}}\right)(r=-0,681)$ (el engorde en corrales generó un incremento en la $\mathrm{PCV}_{\mathrm{SUH}}$ superior a la del sistema de pastoreo), la frecuencia de ECvt-SUH (Pv ESUH $)(r=0,426)$, la tasa de contaminación cruzada entre canales en el frigorífico $\left(\mathrm{T}_{\mathrm{CC}}\right)(r=0,289)$, la frecuencia de ECvt en el sistema de engorde por pastoreo $\left(\mathrm{Pv}_{\mathrm{p}}\right)(r=0,348)$ y la frecuencia de ECvt en los corrales de engorde $\left(\mathrm{Pv}_{\mathrm{f}}\right)$ $(r=0,06)$ (figura 2A).

$\mathrm{Al}$ aumentar la $\mathrm{T}_{\mathrm{CC}}$ la $\mathrm{PCV}_{\mathrm{SUH}}$ también se elevó, por lo que puede servir de indicador de las condiciones sanitarias en las cuales los operarios realizan el faenado.

La proporción de animales portadores de ECvt-SUH ( $\left.\mathrm{Pv}_{\mathrm{ESUH}}\right)$ presentó una correlación significativa con la frecuencia de canales contaminadas $\left(\mathrm{PCV}_{\mathrm{SUH}}\right)$ : a mayor cantidad de animales portadores mayor número de canales contaminadas.

El análisis de sensibilidad para la carga de ECvt-SUH en la canal mostró que las variables con correlación significativa $(P<0,05)$ fueron: la concentración teórica de ECvt-SUH en la piel de los bovinos $\left(C_{\text {VTP }}\right)(r=0,702)$, el factor de transferencia de ECvt-SUH de la piel a la canal $\left(\mathrm{FT}_{\mathrm{PC}}\right)$ $(r=-0,56)$, la proporción de aislamientos de ECvt-SUH no considerada en el muestreo $\left(\mathrm{Pvt}_{\mathrm{NoM}}\right)(r=0,278)$, la superficie contaminada de una canal (Esc) $(r=0,205)$ y la reducción de ECvt-SUH por el lavado $\left(\mathrm{MR}_{\mathrm{V}} \mathrm{L}\right)(r=-0,11)$ (figura 2B).

La concentración teórica de ECvt-SUH en la piel de los bovinos $\left(\mathrm{C}_{\mathrm{VTP}}\right)$ fue la variable que presentó la mayor correlación con la carga bacteriana final $\left(\mathrm{CB}_{\mathrm{F}}\right)$, lo que indica la importancia que tiene el desollado en la transferencia de ECvt-SUH de la piel a la canal. El valor negativo del $\mathrm{FT}_{\mathrm{PC}}$ refleja el efecto de la transferencia bacteriana de la piel del animal a la canal durante el desollado y cuanto menor es el $\mathrm{FT}_{\mathrm{PC}}$, menos bacterias permanecerán en la piel y mayor será el traspaso de bacterias de la piel a la canal.

La proporción de ECvt-SUH no considerada en el muestreo $\left(\mathrm{Pvt}_{\mathrm{NoM}}\right)$ presentó una correlación positiva con la $\mathrm{CB}_{\mathrm{F}}$, lo que demuestra la importancia de corregir los modelos predictivos en función de las limitantes que presentan los métodos microbiológicos disponibles. $\mathrm{La} \mathrm{CB}_{\mathrm{F}}$ en la canal tuvo una correlación positiva con la superficie susceptible de resultar contaminada (Esc).

\section{Análisis de sensibilidad avanzado}

Con las iteraciones del análisis de la $\mathrm{PCV}_{\text {SUH }}$ y la probabilidad de que un animal se críe bajo el sistema de pastoreo o en corrales de engorde $\left(\mathrm{Pb}_{\mathrm{P}-\mathrm{F}}\right)$ se determinó que el promedio de canales infectadas con ECvt-SUH en el frigorífico sería de 0,33 (IC95\%: 0,31 a 0,36) para animales provenientes de pastoreo y de 0,51 (IC95\%: 0,48 a 0,53) para los engordados en corrales. La probabilidad de encon- 
FIGURA 1. Distribución de la probabilidad acumulada de la frecuencia de canales contaminadas con Escherichia coli verotoxigénica (ECvt) asociada con el síndrome urémico hemolítico (ECvt-SUH) (A) y la carga final de ECvt en las canales (B)

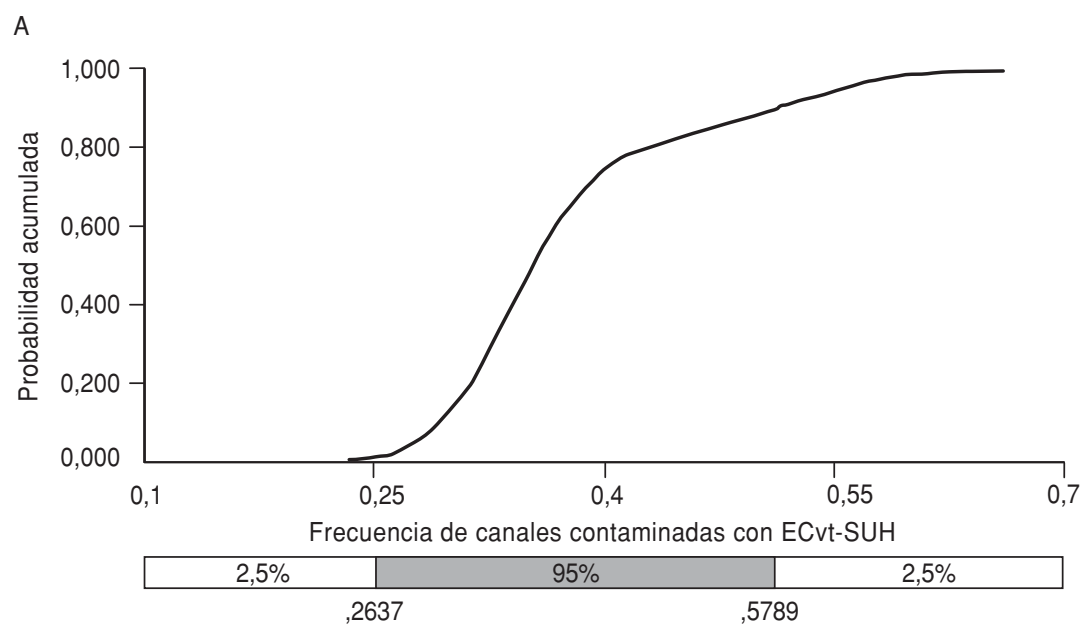

B

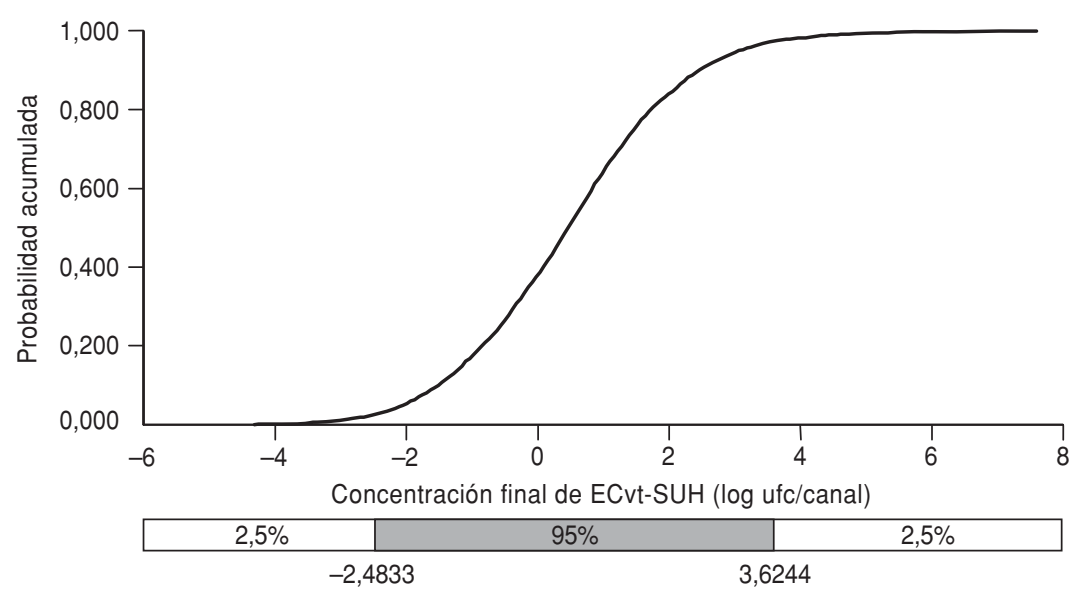

trar una canal con ECvt-SUH después del desollado en el frigorífico fue 1,5 veces (IC95\%: 1,10 a 2,16) mayor en bovinos engordados en corrales que en los provenientes del sistema de pastoreo $(P=0,009)$. La PCV $\mathrm{SUH}_{\mathrm{S}}$ se elevó al aumentar los percentiles de la variable de entrada $\mathrm{Pv}_{\mathrm{ESUH}}$. Por lo tanto, la probabilidad de encontrar una canal infectada con ECvt-SUH en el frigorífico fue 1,5 veces (IC95\%: 1,21 a 1,90) mayor en el percentil 99 (con una frecuencia de 0,76 ) que en el percentil 1 (con una frecuencia de 0,50$)(P<0,001)$.

Los cambios en cada percentil de la $\mathrm{T}_{\mathrm{CC}}$ generaron un efecto significativo sobre la $\mathrm{PCV}_{\mathrm{SUH}^{\prime}}$ con 1,2 veces (IC95\%: 0,98 a 1,71) más riesgo de encontrar una canal infectada después del desollado en el percentil 99 que en el percentil $1(P=0,08)$ de la distribución de la $\mathrm{T}_{\mathrm{CC}}$.

Cuando se empleó el percentil 1 de la distribución de la probabilidad de la conufc/canal, en promedio.
(IC95\%: $-1,00$ a 0,25) y para el percentil $99(1,72 \log$ ufc) de 1,14 $\log$ ufc (IC $95 \%$ : 1,14 a 1,66). Esto generó una diferencia de 1,12 log ufc entre los valores extremos de la distribución de la variable de entrada. Por lo tanto, a medida que aumentó el número de ECvt-SUH no considerada en el muestreo se incrementó la concentración final de esas bacterias.

Los cambios en la $\mathrm{CB}_{\mathrm{F}}$ promovidos por el factor de transferencia de ECvtSUH de la piel a la canal fue de 2,37 log ufc/canal (IC95\%: 1,70 a 2,89) para el percentil $1(0,27 \log$ ufc) y de $-1,35 \log$ ufc/canal (IC95\%: -2,10 a -0,80) para el percentil 99 (4,22 log ufc). Por lo tanto, la diferencia de percentiles manifestó una reducción de la carga bacteriana después del desollado de 2,36 log ufc a medida que se incrementó el número de estas bacterias que no se transfirieron desde la piel a la canal.

Otro factor de reducción de ECvt-SUH en el frigorífico fue el lavado de las canales con agua potable. El efecto del baño sobre la concentración final de ECvt$\mathrm{SUH}$ en las canales fue de 0,84 log ufc/canal (IC95\%: 0,13 a 1,37) para el percentil $1(0,07 \log$ ufc) y de 0,11 log ufc/canal (IC95\%: $-0,60$ a 0,65) para el percentil $99(0,84 \log$ ufc). Por lo tanto, la reducción en la carga final de ECvt-SUH en una canal lavada fue de 5,63 log ufc menos con respecto a una canal no lavada o lavada de forma inadecuada.

\section{Análisis de escenarios}

La vacunación redujo significativacentración de ECvt-SUH en la piel de los bovinos $\left(-1,43 \log\right.$ ufc $\left./ \mathrm{cm}^{2}\right)$ sobre la $\mathrm{CB}_{\mathrm{F}}$, el resultado fue de $-1,65 \log$ ufc/canal (IC95\%: $-2,42$ a 1,10) y con el percentil $99\left(4,9 \log \mathrm{ufc} / \mathrm{cm}^{2}\right)$ fue de 4,32 log ufc/canal (IC95\%: 3,67 a 4,81). Con el incremento en la concentración de ECvtSUH en la piel de los bovinos (de $-1,43$ $\log \mathrm{ufc} / \mathrm{cm}^{2}$ en el percentil 1 a $4,9 \log$ ufc $/ \mathrm{cm}^{2}$ en el percentil 99) aumentó la carga final de ECvt-SUH en 5,97 log

Con el fin de reducir la incertidumbre y aproximar el modelo a la realidad, se estimó el número de ECvt-SUH no consideradas en el muestreo $\left(\mathrm{Pvt}_{\mathrm{NoM}}\right)$ debido a las limitaciones propias de las técnicas analíticas. El resultado de las iteraciones determinó que la carga promedio de ECvt-SUH para el percentil 1 de la distribución de bacterias no recuperadas en los muestreos microbiológi$\cos (0,21 \log$ ufc) fue de $-0,27 \log$ ufc mente la frecuencia de ECvt-SUH en los bovinos. La frecuencia en el grupo de bovinos vacunados fue de 0,20 (IC95\%: 0,0 a $0,53)$, mientras que para los no vacunados fue de 0,37 (IC95\%: 0,26 a 0,58), con 1,8 veces (IC95\%: 1,15 a 2,95) menos riesgo de observar una canal infectada con ECvtSUH en los bovinos vacunados que en los no vacunados (figura 3A); esto representa una reducción de 54,1\%. La carga final de ECvt-SUH en los animales vacunados fue de $-0,62 \log$ ufc/canal (IC95\%: $-3,84$ a $2,87)$, mientras en los no vacunados fue de 0,47 log ufc/canal (IC95\%: -2,46 a $3,62)$. El efecto generado por la vacunación sobre la carga final de ECvt-SUH fue de $0,43 \log$ ufc/canal menos con respecto a los no vacunados (figura $3 \mathrm{~B}$ ).

En el escenario de duchado de canales con productos orgánicos, la carga final de ECvt-SUH fue de -0,53 log ufc/canal (IC95\%: $-3,77$ a 2,94), mientras que para 
FIGURA 2. Resultados del análisis de sensibilidad de la frecuencia de canales contaminadas con Escherichia coli verotoxigénica (ECvt) asociada con el síndrome urémico hemolítico (ECvt-SUH) (A) y la carga final de ECvt en la canal (B)

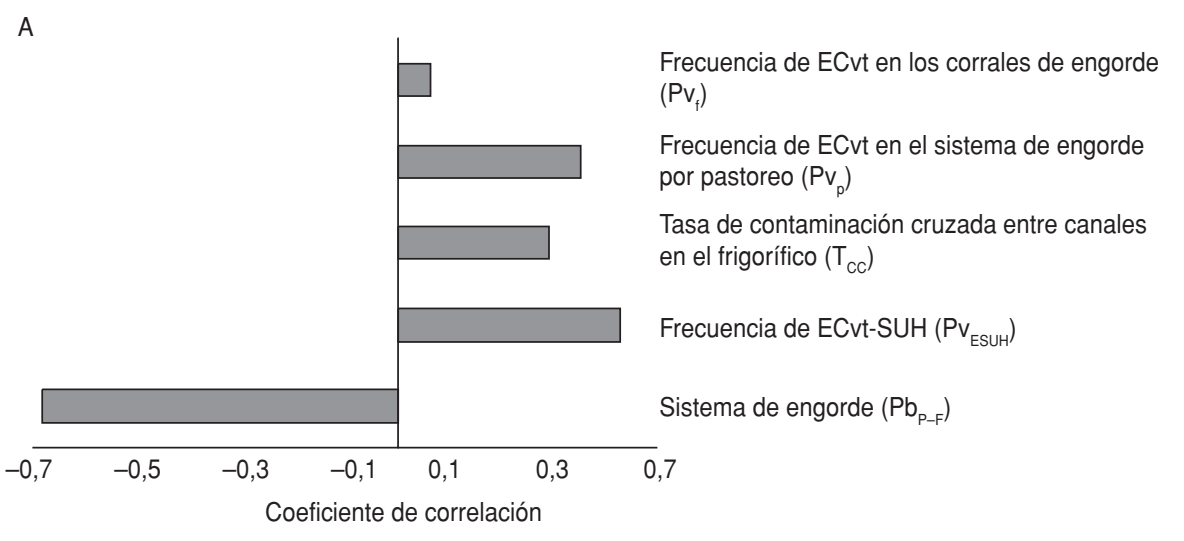

$\mathrm{B}$

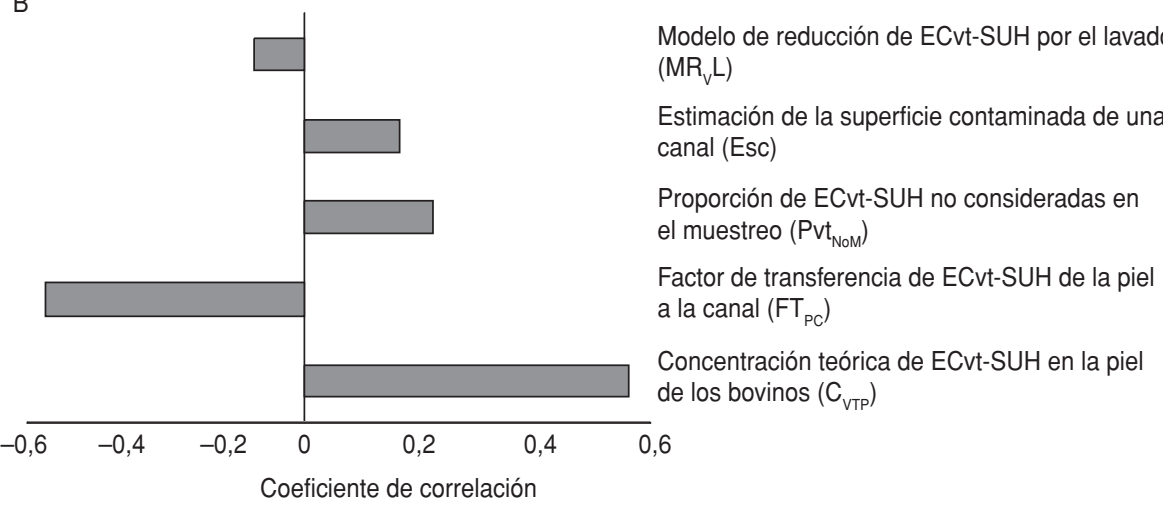

el modelo basal fue de 0,47 log ufc/canal (IC95\%: $-2,46$ a 3,62). La carga final de ECvt-SUH se redujo 0,42 log ufc/canal con respecto al modelo basal (figura 3B). Sin embargo, la frecuencia de ECvt en el escenario de lavado de canales con ácidos orgánicos fue de 0,37 (IC95\%: 0,26 a $0,57)$, un valor similar al estimado en el modelo basal (figura 3A).

El incremento de la proporción de animales engordados en corrales generaría una frecuencia de canales infectadas con ECvt-SUH en el frigorífico de 0,41 (IC95\%: $0,27$ a 0,60$)$, superior a la del modelo basal, que fue de 0,37 (IC95\%: 0,26 a 0,58). Con el engorde en corrales se tuvo 1,1 veces (IC95\%: 0,78 a 1,56) más probabilidad de encontrar una canal infectada en el frigorífico que con el modelo basal, aunque sin significación estadística $(P=0,56)$ (figura $3 \mathrm{~A}$ ). La carga final de ECvt-SUH en las canales bovinas durante su última etapa en el frigorífico fue de 2,03 log ufc/canal (IC95\%: -3,07 a 3,36) en los animales criados en corrales de engorde y de 0,47 log ufc/canal (IC95\%: -2,46 a 3,62) en el modelo basal, con un aumento de 1,56 $\log$ ufc/canal (figura 3B).

\section{DISCUSIÓN}

En diversos países se han realizado evaluaciones cuantitativas del riesgo de exposición a ECvt por consumo de carne bovina. En Canadá (40), Francia (41), Holanda (42), Irlanda $(25,43)$ y los Estados Unidos (28) se ha empleado un mismo modelo, que parte de la producción primaria y termina en el consumo del alimento, aunque ajustado a la realidad epidemiológica (frecuencia y carga) de cada país (41). Por ello se consideró necesario desarrollar un modelo que contemplase las características propias de la cadena agroindustrial de la carne bovina en Argentina, de manera de favorecer su aplicación en el diseño de medidas específicas para el control de ese riesgo en el país.

Las principales discrepancias entre el modelo que se presenta y los ya publicados radican en el tipo de sistema de engorde del ganado bovino y en las cepas de ECvt tomadas en cuenta. En Argentina, el engorde de bovinos se realiza fundamentalmente mediante el sistema de pastoreo (15), mientras que en los países industrializados se emplea principal- mente el sistema de engorde en corrales (44). El serotipo empleado en los modelos internacionales es el O157:H7 (25, 40-43), mientras que para el presente estudio se tomaron los serotipos relacionados con el SUH aislados en Argentina (16-19). Si bien existe un modelo publicado para las condiciones argentinas (32), en el presente modelo se incorporan dos importantes elementos que permiten una aproximación más exacta a la realidad: el empleo diferenciado de dos sistemas de engorde y la determinación de la superficie de las canales.

La frecuencia de ECvt en los animales engordados en corrales se modeló a partir de los datos aportados por la única publicación disponible en Argentina con las características requeridas (19). Esta limitación en la información disponible generó incertidumbre; no obstante, la frecuencia utilizada de ECvt en animales engordados en corrales, equivalente a $37,0 \%$, fue similar a los valores de $44,5 \%$ y $43,0 \%$ informados en el Reino Unido (24) y los Estados Unidos (26), respectivamente.

La correlación entre el sistema de engorde bovino en corrales y la frecuencia de ECvt en las canales coincidió con otros estudios (45). La mayor frecuencia de ECvt encontrada en los bovinos engordados en corrales puede ser consecuencia del reducido espacio disponible en los corrales, que provoca un mayor contacto entre los animales y el aumento del riesgo de transmisión horizontal (45). Los bovinos que ingresan al sistema de corrales de engorde en Argentina son generalmente animales recién destetados $(15,38)$ y es un hecho comprobado que la frecuencia de ECvt en los animales jóvenes es mayor que en los adultos (10).

La frecuencia de ECvt en el sistema de engorde en corrales $\left(\mathrm{Pv}_{\mathrm{f}}\right)$ generó los mayores cambios en la frecuencia de ECvt en las canales. Una posible explicación podría ser que la alimentación que reciben los animales para acelerar el aumento de peso se basa fundamentalmente en granos. Las ECvt son capaces de fermentar los azucares liberados por los granos en el colon, lo que ayuda a una mayor supervivencia y proliferación microbianas y aumenta la excreción de este microorganismo patógeno en las heces $(9,12)$.

La variable tasa de contaminación cruzada $\left(\mathrm{T}_{\mathrm{CC}}\right)$ presentó una correlación positiva con la frecuencia de las canales contaminadas con ECvt, de manera similar a lo observado en otros estudios (40). Esta proporción puede verse modificada 
FIGURA 3. Probabilidad acumulada de la frecuencia (A) y la concentración final (B) estimadas de Escherichia coli verotoxigénica asociada con el síndrome urémico hemolítico (ECvt-SUH) en los escenarios de vacunación de bovinos, duchado de canales con ácidos orgánicos e incremento en el sistema de engorde en corrales

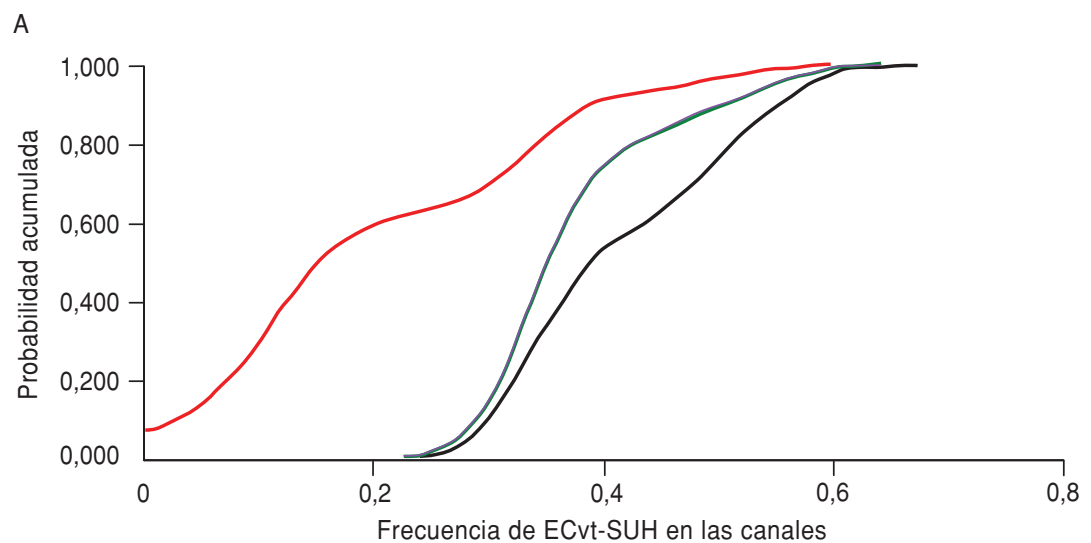

B

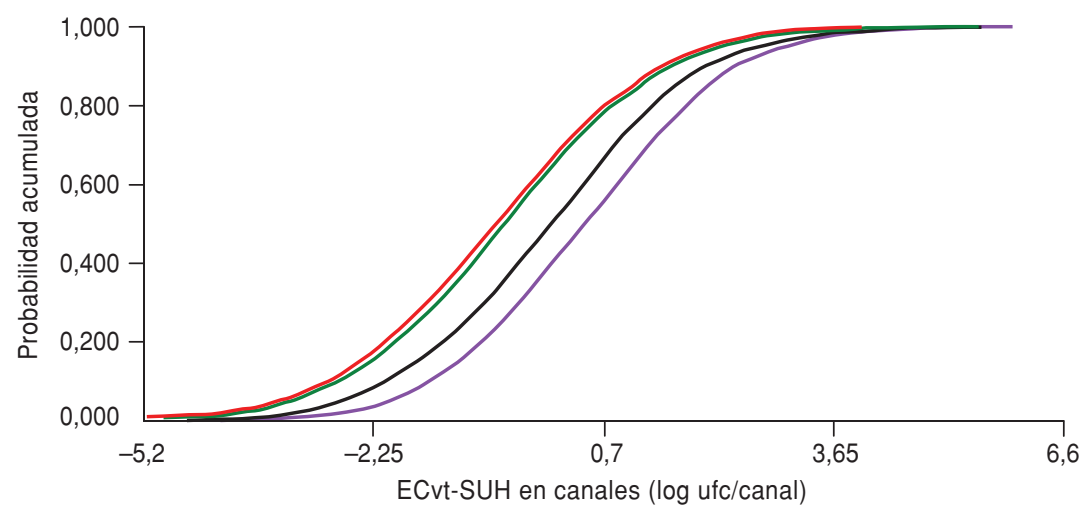

Escenario basal __ ; escenario de duchado de canales _— ; escenario de incremento de corrales de engorde _— ; escenario de vacunación _ـ.

Notas: En la figura A, las curvas correspondientes al escenario basal y al duchado de canales se sobreponen. Las líneas en esta figura solo se pueden diferenciar en versión electrónica o en una impresión a colores.

por dos factores: la autocontaminación y la contaminación cruzada entre canales. En el primer caso, los animales que excretan ECvt en las heces pueden contaminar su propia carne durante el faenado (por ejemplo, por aerosoles de heces provenientes de la región anal, el contacto de la piel con la carne y la ruptura de las vísceras, entre otros); se considera que esta contaminación de la piel a la canal es inevitable (40). En el segundo caso, el animal y la canal se encuentran libres del patógeno y resultan contaminados por las heces contaminadas excretadas por otros animales faenados (44). Esta etapa se modeló a partir de datos estadounidenses publicados, sin perjuicio de los resultados ya que el proceso de faenado de los bovinos es similar en los frigoríficos de los Estados Unidos (46) y Argentina (30).
Si bien los otros modelos publicados se han basado en el serotipo O157:H7 de ECvt por haber causado varios brotes entéricos hemorrágicos y SUH en esos países $(12,25,40-43)$, solo $50 \%$ de los casos de SUH notificados en Argentina se deben al serotipo O157:H7. El resto está asociado con otras cepas no relacionadas con el grupo de serotipos O157 (10); en productos cárnicos se han aislado además otros cinco serotipos: O113:H21, O8:H19, O145:NM, O25:H2 y O121:H19 (18). La integración en el modelo matemático de todos estos serotipos de ECvtSUH generó una mayor carga teórica final de ECvt $\left(\mathrm{CB}_{\mathrm{F}}\right)$ en las canales bovinas, en comparación con los informados en otros estudios similares (25, 40-43).

La concentración teórica de ECvt en la piel de los bovinos $\left(\mathrm{C}_{\mathrm{VTP}}\right)$ fue la variable con mayor correlación con la $\mathrm{CB}_{\mathrm{F}}$, lo que coincide con lo informado por otros autores (40). Según estos resultados, una mayor carga de ECvt en la piel de los animales incrementa las probabilidades de transferencia de bacterias a las canales durante el proceso de sacrificio y faenado $(25,44,47)$. La variable $C_{\text {VTP }}$ agregó incertidumbre al modelo por la ausencia de datos nacionales. Se deben realizar estudios en Argentina para determinar la carga del patógeno en los bovinos y poder ajustar el modelo.

La variable factor de transferencia de ECvt-SUH de la piel a la canal $\left(\mathrm{FT}_{\mathrm{PC}}\right)$ también se construyó a partir de la información extranjera disponible (23), debido a la falta de datos nacionales. Como el proceso de sacrificio y faenado de animales en Argentina es similar al de los países de donde provenían esos datos, se estima que esto no afecta negativamente a este modelo.

Todas las metodologías de recuento microbiano disponibles presentan algún grado de subestimación. Al ajustar la carga bacteriana que se transfiere de la piel a la canal se redujo la incertidumbre sobre la carga real de ECvt en la canal. A pesar de que esta variable se construyó con información extranjera, esto no aportó una mayor incertidumbre debido a que se trata de ajustes de técnicas microbiológicas estándares empleadas por igual en todos los países.

La falta de estudios científicos que permitan estimar la superficie total de una canal que se contamina durante el proceso de sacrificio genera incertidumbre (25), por lo que para modelar esta etapa, por lo general se toma arbitrariamente una superficie. En el presente estudio se tomaron las medidas de la superficie de las canales de bovinos en un frigorífico local, lo que permitió obtener datos ajustados a los biotipos y sistemas productivos empleados en Argentina y estimar con mayor precisión la superficie total susceptible de contaminarse durante el faenado de los bovinos.

En el modelo matemático se predijo una carga promedio de ECvt-SUH de $2,9 \mathrm{ufc} /$ canal (0,473 log ufc/canal), sin embargo, esta valor podría aumentar hasta $4168 \mathrm{ufc/canal} \mathrm{(3,62} \mathrm{log} \mathrm{ufc/canal).}$ Un incremento en la carga bacteriana final aumentaría el riesgo de exposición de las personas a ECvt-SUH por consumo de carne contaminada $(25,43)$, lo que se puede considerar un riesgo alimentario para la salud de las personas (47).

La incertidumbre es inevitable en cualquier evaluación de riesgos, pero se 
deben identificar y reconocer, y discutir su efecto en el modelo (48). Por lo tanto, las futuras investigaciones para reducir las incertidumbres del modelo deben estar dirigidas a mejorar la estimación en la frecuencia de ECvt-SUH en el sistema de engorde en corrales, determinar la frecuencia de heces contaminadas antes del desollado y estimar la concentración de ECvt-SUH en la piel.

La información generada por el presente modelo debe ayudar al diseño de estrategias de control y comunicación del riesgo de SUH y la adopción de medidas de control adecuadas para cada una de las etapas sensibles identificadas en el proceso. No obstante, antes de aplicar medidas de control se requiere evaluar su efectividad en términos de frecuencia y extensión de la exposición a ECvt-SUH (2).

A partir de los resultados del análisis de sensibilidad se identificaron dos variables estrechamente relacionadas con la proporción de canales contaminadas con ECvt-SUH y la carga bacteriana final en la canal, y se construyeron dos estrategias hipotéticas de mitigación de la contaminación con ECvt-SUH en los bovinos en pie y en las canales: la vacunación y el lavado de las canales con ácidos orgánicos.

Dado que la frecuencia de ECvt-SUH en la piel de los bovinos es uno de los factores más importantes en el riesgo de infección, se deben implementar acciones dirigidas a reducir la contaminación con este patógeno en los sistemas de explotación primaria. $(12,13)$. Para ello se recomienda la vacunación, por su especificidad y facilidad de aplicación y por no alterar las actividades habituales dentro del sistema de explotación ganadera.

El escenario para la vacunación de bovinos se construyó con información bibliográfica extranjera (34). Teniendo en cuenta la reacción inmunológica cruzada entre las proteínas del sistema de secreción tipo III (conocidas como TTSS, por sus siglas en ingles) de los distintos subtipos de esta bacteria, se podría esperar que la inmunización con una o varias de estas proteínas protejan contra las ECvt más frecuentes asociadas con la infección grave en humanos $(12,34)$.

El escenario de vacunación permitió predecir una reducción de la frecuencia de canales bovinas contaminadas con ECvt, aunque no redujo significativamente la carga de ECvt. Esto podría deberse a la contaminación cruzada en el frigorífico $(25,40,42-44,47)$. Una de las principales desventajas de esta medida de mitigación es que, como las ECvt no ocasionan enfermedades en los animales vivos $(9,12,13)$, los ganaderos no tienen incentivos para aplicar la vacunación, a menos que intervengan instituciones gubernamentales como el Ministerio de Salud y el Ministerio de Agricultura, y se cree conciencia en la comunidad ganadera sobre la necesidad de esta práctica.

En cuanto al duchado de las canales con ácidos orgánicos, esta es una medida factible para reducir la contaminación con ECvt-SUH dentro del frigorífico. En Argentina está permitida su utilización como antimicrobiano para el enjuague final de las canales antes del enfriamiento (21), pero no se utiliza habitualmente. El escenario basado en el duchado de todas las canales con ácidos orgánicos antes de pasarlas a la cámara fría permitió reducir significativamente la carga final de ECvt-SUH. Sin embargo, el resultado presentó un espectro muy amplio, de $-2,46 \log$ ufc/canal a 3,62 log ufc/canal, lo que demuestra que si bien el duchado con ácidos orgánicos reduce la carga de ECvt-SUH en la canal, no la elimina por completo ni compensa errores generados durante el faenado de los animales.

Por otra parte, los ácidos orgánicos permiten reducir la carga de ECvt-SUH, pero no la frecuencia, es decir, si no se controla el número de animales que ingresan al faenado con ECvt-SUH en las heces, el impacto de esta medida sería limitado $(36,37,49)$. La principal desventaja que podría generar el duchado de las canales con ácidos orgánicos son los cambios indeseables en el color de la carne: una mayor luminosidad y tonalidad e inferior índice de decoloración (50); esto favorece el rechazo por parte de los consumidores dada las exigencias en la cultura gastronómica del país (51).

Dado que ambas estrategias impactan sobre aspectos diferentes pero complementarios de la exposición (frecuencia y carga bacteriana), se sugiere la aplicación conjunta de las dos estrategias de mitigación.

Hasta el presente, el engorde en corrales concentra $20 \%$ de la producción argentina de carne vacuna $(10,15,38,45)$. El avance de la frontera agrícola para la producción de granos (38) está desplazando a los productores ganaderos hacia zonas no aptas para el pastoreo, lo que puede generar un aumento en la partici- pación de los sistemas intensivos de engorde. En este estudio se estimó que en los próximos 10 años esta participación podría ser de 50 a $60 \%$ de la producción nacional. Bajo este escenario la frecuencia de ECvt-SUH podría aumentar entre 15 y $23 \%$ con respecto al modelo basal. Lo anterior ocasionaría un considerable incremento en el riesgo de exposición a ECvtSUH y, muy probablemente, llevaría a un aumento en la incidencia de SUH.

El presente modelo demostró su validez para estimar la frecuencia de canales contaminadas con ECvt-SUH así como el número de bacterias presentes en ellas en diferentes escenarios. La frecuencia de la contaminación con ECvt-SUH en los bovinos engordados intensivamente en corrales fue la variable con mayor impacto sobre la contaminación con esta bacteria patógena en las canales antes de la salida del frigorífico, mientras que la carga final del patógeno fue altamente sensible a la concentración de ECvt en la piel de los animales. De esta forma la producción primaria de bovinos fue la etapa del proceso que mayor efecto negativo tuvo en la exposición al patógeno. Las condiciones en las cuales se realiza el desollado de los bovinos fue la etapa con mayor efecto negativo en la exposición a ECvt-SUH dentro de los frigoríficos.

De acuerdo con lo anterior, las intervenciones que se realicen en la producción primaria de bovinos, como la vacunación, tendientes a disminuir o suprimir la liberación de ECvt-SUH en las heces, son las más útiles para reducir el ingreso de esta bacteria a la cadena agroindustrial de la carne de res. Las medidas aplicadas en etapas posteriores, como el duchado con soluciones de ácidos orgánicos, aunque generan reducciones en el número de bacterias presentes en el alimento, son menos eficaces.

La intensificación de la producción ganadera genera un incremento en los riesgos a la salud pública por una mayor exposición a los patógenos como ECvt-SUH. Este tipo de escenarios debe tomarse en cuenta, tanto por los sectores productores como por las dependencias gubernamentales responsables de la Salud Pública, con el fin de evaluar y reducir los efectos negativos de esta práctica en la salud de la población. Para reducir la incertidumbre en el modelo propuesto es necesario desarrollar investigaciones nacionales dirigidas a estimar la carga de ECvt en la piel de los animales y las canales. 


\section{REFERENCIAS}

1. Tozzi EA, Gorietti S, Caprioli A. Epidemiology of human infections by Escherichia coli O157 and other verocytoxin-producing E. coli. En: Duffy G, Garvey P, McDowell DA. Verocytotoxigenic E. coli. Trumbull, CT: Food \& Nutrition Press; 2001. Pp. 161-80.

2. Programa Conjunto FAO/OMS sobre Normas Alimentarias, Comité del CODEX sobre Higiene de los Alimentos. Perfil de riesgos para E. coli enterohemorrágica, incluyendo la identificación de los productos de interés, incluso los bretones, carne de res molida y puerco. 35a Reunión del Comité del CODEX sobre Higiene de los Alimentos; 2003 enero 27 a febrero 1; Orlando, Estados Unidos de América. (Tema 1 del Programa CX/FH 03/ 5-Ad. 4.)

3. Cortés OIA, Rodríguez AG, Moreno EEA, Tenorio LJM, Torres MBP, Montiel V. Brote causado por Escherichia coli en Chalco, México. Salud Publica Mex. 2002;44:297-302.

4. Máttar S, Visbal SJ, Arrieta G. E. coli O157: H7 enterohemorrágica: un agente etiológico de diarrea y zoonosis en Colombia subestimado. Rev MVZ Córdoba. 2001;6(1):15-23.

5. Blanco M, Padola LN, Krüger A, Sanz ME, Blanco EJ, González AE, et al. Virulence genes and intimin types of Shiga-toxin-producing Escherichia coli isolated from cattle and beef products in Argentina. Int Microbiol. 2004;7: 269-76.

6. Cordero RM, Barretos AG, Sanchén CA, Hernández CIR. Diagnóstico de Escherichia coli enterohemorrágica en niños con diarreas. Arch Med Camagüey. 2006;10:1025-55.

7. Barslund AS, Benítez AJ, Parra HL, Wilka NN. Síndrome urémico hemolítico. Rev Postgrado VI Catedra Med. 2007;170:16-20.

8. Rivas M, Miliwebsky E, Chinen I, Deza N, Leotta AG. Epidemiología del síndrome urémico hemolítico en Argentina. Diagnostico del agente etiológico, reservorios y vías de transmisión. Medicina (Buenos Aires). 2006; 66(3):27-32.

9. Rivas M, Miliwebsky E, Chinen I, Deza N. Manual de procedimientos diagnóstico y caracterización de Escherichia coli $\mathrm{O} 157$ productor de toxina shiga a partir de especímenes clínicos. Buenos Aires: Instituto Nacional de Enfermedades Infecciosas; 2007.

10. Rivero AM, Padola LN, Etcheverria IA, Parma EA. Escherichia coli enterohemorrágica y síndrome urémico hemolítico en Argentina. Medicina (Buenos Aires). 2004;64:352-6.

11. Rivas M. Síndrome urémico hemolítico. Primer Taller de Validación y Adaptación de Metodologías de Fijación de Prioridades en la Selección de Investigaciones en Salud en Argentina; 2006 mayo 4-5; Olavarría, Buenos Aires, Argentina. Buenos Aires: Ministerio de Salud y Ambiente; 2006.

12. Mercado CE. Síndrome urémico hemolítico: ¿por qué Argentina? Rev Argent Microbiol. 2007;39:191-2.

13. Fairbrother MJ, Nadeau E. Contaminación de animales por Escherichia coli en la finca. Rev Sci Technol Off Int Epizoology. 2006;25:565-6.

14. Luna CJ, Signorini PM, Díaz GR, Ordóñez MBL. Evaluación de riesgos en alimentos. México, D.F.: International Life Sciences Institute; 2009.
15. Oficina Nacional de Control Comercial Agropecuario. Informe mensual de carnes. Bovinos. 2008. Información electrónica. Buenos Aires: ONCCA; 2009. Hallado en http:// www.oncca.gov.ar/documentos/mensual noviembre_bovinos.pdf. Acceso el 13 de junio de 2010.

16. Sanz ME, Viñas MR, Parma AE. Prevalence of bovine verotoxin-producing Escherichia coli in Argentina. Eur J Epidemiol. 1998;14:399-403.

17. Notario R, Fain JC, Prado V, Ríos M, Borda N, Gambande T. Prevalence of enterohemorrhagic Escherichia coli in a cattle area of Argentina. Genotypic characterization of the strains of animal origin. Rev Med Chile. 2000; 128:1335-41.

18. Meichtri L, Miliwebsky E, Gioffré A, Chinen I, Baschkier A, Chillemi G, et al. Shiga toxinproducing Escherichia coli in healthy young beef steers from Argentina: prevalence and virulence properties. Int J Food Microbiol. 2004;96:189-98.

19. Padola NL, Sanz ME, Blanco JE, Blanco M, Blanco J, Etcheverria AI, et al. Serotypes and virulence genes of bovine shigatoxigenic Escherichia coli (STEC) isolated from a feedlot in Argentina. Vet Microbiol. 2004;100:3-9.

20. Schuehle-Pfeiffer EC, King AD, Lucia ML, Cabrera-Díaz E, Acuff RG, Randel DR, et al. Influence of transportation stress and animal temperament on fecal shedding of Escherichia coli O157:H7 in feedlot cattle. Meat Sci. 2009; 81:300-6.

21. República Argentina, Secretaría de Agricultura, Ganadería, Pesca y Alimentos. Código Alimentario Argentino (CAA). Decreto 4238/68: reglamento de inspección de productos, subproductos y derivados de origen animal 1999. Buenos Aires: SAGPyA; 1999. Hallado en http://www.alimentosargentinos.gov.ar/ programa_calidad/Marco_Regulatorio/Decreto _4238/Decreto4238-68.htm. Acceso el 13 de junio de 2010.

22. Bell GR. Distribution and sources of microbial contamination on beef carcasses. J Appl Microbiol. 1997;82:292-300.

23. Bacon RT, Belk KE, Sofos JN, Smith GC. Incidence of Escherichia coli O157:H7 on hide, carcass and beef trimmings samples collected from United States packing plants. Food Safety and Inspection Service Public Meeting on E. coli O157:H7; 2000 febrero 29; Arlington, Virginia, Estados Unidos de América. Fort Collins, CO: USDA-APHIS; 2000.

24. McEvoy JM, Doherty AM, Sheridan JJ, Thomson-Carter FM, Garvey P, McGuire L, et al. The prevalence and spread of Escherichia coli O157: H7 at a commercial beef abattoir. J Appl Microbiol. 2003;95:256-66.

25. Cummins E, Nally P, Butler F, Duffy G, O’Brien S. Development and validation of a probabilistic second-order exposure assessment model for Escherichia coli O157:H7 contamination of beef trimmings from Irish meat plants. Meat Sci. 2008;79:139-54.

26. Elder RO, Keen JE, Siragusa GR, BarkocyGallagher GA, Koohmaraie M, Laegreid WW. Correlation of enterohemorrhagic Escherichia coli $\mathrm{O} 157$ prevalence in faeces, hides, and carcasses of beef cattle during processing. Proc Nat Acad Sci USA. 2000;97:2999-3003.
27. O'Brien SB, Duffy G, Carney G, Sheridan JJ, McDowell DA, Blair IS. Prevalence and numbers of Escherichia coli O157 on bovine hide at a beef slaughter plant. Int J Food Microbiol. 2005;68;660-5.

28. Ebel E, Schlosser W, Kause J, Orloski K, Roberts T, Narrod C. Draft risk assessment of the public health impact of Escherichia coli O157 in ground beef. Int J Food Microbiol. 2004;67:1991-9.

29. Siragusa RG, Nawotka K, Spilman DS, Contag RP, Contag HC. Real-time monitoring of Escherichia coli O157:H7 adherence to beef carcass surface tissues with a bioluminescent reporter. Appl Environ Microbiol. 1999;65(4): 1738-45.

30. Gill CO, McGinnis JC, Badoni M. Use of total Escherichia coli counts to assess the hygienic characteristics of a beef carcass during processing. Int J Food Microbiol. 1996;31:181-96.

31. Signorini ML. Modelo matemático predictivo del crecimiento de Escherichia coli $\mathrm{O} 157$ en carne vacuna. InVet. 2008;8(1):47-57.

32. Signorini M, Tarabla H. Quantitative risk assessment for verocytotoxigenic Escherichia coli in ground beef hamburgers in Argentina. Int J Food Microbiol. 2008;132:153-61.

33. World Organization for Animal Health. Handbook on import risk analysis for animals and animal products. Quantitative risk assessment. Paris: Office Internationale des Epizooties; 2004;2:51-104.

34. Potter AA, Klashinsky S, Li Y, Frey E, Townsend H, Rogan D. Decreased shedding of Escherichia coli O157:H7 by cattle following vaccination with type III secreted proteins. Vaccine. 2004;22:362-9.

35. Terrance MA, Bosilevac MJ, Nou X, Shackelford DS, Wheeler LT, Kent, PM, et al. Escherichia coli $\mathrm{O} 157$ prevalence and enumeration of aerobic bacteria, Enterobacteriaceae, and Escherichia coli $\mathrm{O} 157$ at various steps in commercial beef processing plants. J Food Prot. 2004;67(4):658-65.

36. Bosilevac MJ, Nou X, Osborn SM, Allen MD, Koohmaraie M. Development and evaluation of an on-line hide decontamination procedure for use in a commercial beef processing plant. J Food Prot. 2005;68(2):265-72.

37. Ojeda C, Vásquez VG. Aplicación de ácidos orgánicos en la reducción de microorganismos aerobios mesófilos y coliformes totales y fecales en canales de bovinos. Rev Tec ESPOL. 2009;20(20). Hallado en http://www.dspace. espol.edu.ec/handle/123456789/210. Acceso el 13 de junio de 2010.

38. Silva RA. Sector Ganado y Carne Vacunos Argentino: caracterización económica y productiva. Primer Congreso Regional de Economistas Agrarios; 2004 noviembre 3-5; Mar del Plata, Argentina. Hallado en http://www. ipcva.com.ar/files/trabajo41.pdf. Acceso el 13 de junio de 2010.

39. Cámara Argentina de Feedlot. El engorde a corral en la Argentina, evolución y actualidad; Buenos Aires: CAFL; 2009. Hallado en http://www.emprendimientosagropecuarios. com/conecar/ponencias/C006. Ag String agro Conecar [Informe El Feedlot en Argentina-marzo 2009].pdf. Acceso el 13 de junio de 2010. 
40. Cassin HM, Lammerding MA, Todd DCE, Ross W, Mccoll SR. Quantitative risk assessment for Escherichia coli O157:H7 ground beef hamburgers. Int J Food Microbiol. 1998;41: 21-44.

41. Delignette-Muller LM, Cornu M. Quantitative risk assessment for Escherichia coli O157:H7 in frozen ground beef patties consumed by young children in French households. Int J Food Microbiol. 2008;128:158-64.

42. Nauta M, Evers E, Takumi K, Havelaar A. Risk assessment of Shiga-like producing Escherichia coli $\mathrm{O} 157$ in steak tartar in the Netherlands. Report 257851003/2001. Bilthoven: Rijks Instituut voor Volksgezondheid en Milieu; 2001:165-9.

43. Duffy G, Cummins E, Nally P, O’Brien S, Butler F. A review of quantitative microbial risk assessment in the management of Escherichia coli O157:H7 on beef. Meat Sci. 2006; 74:76-88.

44. Food Safety and Inspection Service, US Department of Agriculture. Risk assessment of the public health impact of Escherichia coli
O157:H7 in ground beef. FSIS-USDA: Beltsville, MD; 2001

45. Carney E, O'Brien SB, Sheridan JJ, Mcdowell DA, Blair IS, Duffy G. Prevalence and level of Escherichia coli $\mathrm{O} 157$ on beef trimmings, carcasses and boned head meat at a beef slaughter plant. Food Microbiol. 2006;23:52-9.

46. Lasta JA, Gimeno EJ. Hygiene conditions of beef carcasses and cuts in Argentine meat packing plants. Fleischwirtsch. 1993;73:169-71.

47. Mather EA, Reid JWS, Mcewen AS, Ternent EH, Reid-Smith JR, Boerlin P, et al. Factors associated with cross-contamination of hides of Scottish cattle by Escherichia coli O157. Appl Environ Microbiol. 2008;74(20):6313-9.

48. Koohmaraie M, Arthur MT, Bosilevac JM, Guerini M, Shackelford DS, Wheeler LT. Postharvest interventions to reduce/eliminate pathogens in beef. Meat Sci. 2005;71:79-91.

49. Reglamento (CE) No 178/2002 del Parlamento Europeo y del Consejo por el que se establecen los principios y los requisitos generales de la legislación alimentaria, se crea la Autoridad Europea de Seguridad Alimentaria y se fijan procedimientos relativos a la seguridad alimentaria. Diario Oficial de las Comunidades Europeas 2002 febrero 1. Hallado en http://eur-lex.europa.eu/LexUriServ / LexUriServ.do?uri=OJ:L:2002:031:0001:0001: ES:pdf. Acceso el 13 de junio de 2010.

50. Signorini ML. Efecto de la fermentación láctica sobre las propiedades funcionales de las proteínas cárnicas [tesis doctoral]. México, D.F.: Universidad Autónoma Metropolitana, Unidad Iztapalapa; 2002.

51. Brogna AO, González GA. Síndrome urémico hemolítico. Bromatología (Buenos Aires). 2008;36:49-54. Hallado en http://www. cvpba.org.ar/assets/pdf/pdf_st/36_sind. huremico_hem_.pdf. Acceso el 13 de junio de 2010

Manuscrito recibido el 22 de febrero de 2010. Aceptado para publicación, tras revisión, el 11 de junio de 2010.

ABSTRACT Objectives. Quantify contamination by verotoxin-producing Escherichia coli associated with hemolytic uremic syndrome (VTEC-HUS) in cattle carcasses and generate estimates of exposure in three likely scenarios.

Verotoxin-producing Escherichia coli: quantitative model of exposure and risk scenarios in cattle carcasses in Argentina

Key words
Methods. A model was constructed of the frequency and magnitude of VTEC-HUS contamination from primary production to the removal of the carcasses from cold storage, based on the published scientific information, epidemiological data, and information from local experts. The probability distributions that best described each step in the process and scenarios were input to the @ Risk ${ }^{\circledR}$ program with multiple simulations using Monte Carlo analysis. Pearson's correlation test was used for the sensitivity analysis.

Results. The estimated frequency of carcasses with VTEC-HUS was 0.37 (95\% CI: 0.26 to 0.58 ) and the final load of VTEC-HUS was $0.47 \log$ CFU/carcass (95\% CI: -2.46 to 3.62). The most closely related variables were the fattening system $(r=-0.681)$ and the theoretical concentration of VTEC-HUS on the cattle's skin $(r=0.702)$. Vaccinating the animals reduced the frequency of VTEC-HUS in the carcasses by $54.1 \%$, although there were no significant changes in the final VTEC-HUS load. Washing the carcasses reduced the final load by $0.42 \log \mathrm{CFU} /$ carcass compared with the baseline model, without any change in the frequency. A 50\%-60\% increase in the percentage of animals fattened in pens would increase the frequency of carcasses contaminated with VTEC-HUS by $15 \%-23 \%$.

Conclusions. Vaccinating the animals was the most effective scenario for reducing introduction of the bacteria in the beef production chain. Intensifying livestock production will increase the public health risk due to greater exposure to VTEC-HUS.

Shiga-toxigenic Escherichia coli; hemolytic-uremic syndrome; meat industry; risk assessment; Argentina. 